\title{
Using Airborne SAR Interferometry to Measure the Elevation of a Greenland Ice Cap
}

\author{
Dall, Jørgen; Keller, K.; Madsen, S.N.; Forsberg, René
}

Published in:

Proceedings of the IEEE 2000 International Geoscience and Remote Sensing Symposium

Link to article, DOI:

10.1109/IGARSS.2000.858043

Publication date:

2000

Document Version

Publisher's PDF, also known as Version of record

Link back to DTU Orbit

Citation (APA):

Dall, J., Keller, K., Madsen, S. N., \& Forsberg, R. (2000). Using Airborne SAR Interferometry to Measure the Elevation of a Greenland Ice Cap. In Proceedings of the IEEE 2000 International Geoscience and Remote Sensing Symposium IEEE. https://doi.org/10.1109/IGARSS.2000.858043

\section{General rights}

Copyright and moral rights for the publications made accessible in the public portal are retained by the authors and/or other copyright owners and it is a condition of accessing publications that users recognise and abide by the legal requirements associated with these rights.

- Users may download and print one copy of any publication from the public portal for the purpose of private study or research.

- You may not further distribute the material or use it for any profit-making activity or commercial gain

- You may freely distribute the URL identifying the publication in the public portal 


\title{
Using Airborne SAR Interferometry to Measure the Elevation of a Greenland Ice Cap
}

\author{
Jørgen Dall', Søren Nørvang Madsen', Kristian Keller ${ }^{2}$, René Forsberg ${ }^{2}$ \\ ${ }^{1}$ Dept. of Electromagnetic Systems, Technical University of Denmark \\ Ørsteds Plads, Build. 348, DK-2800 Kgs. Lyngby, Denmark \\ Phone: +45 45253800 / Fax: +45 45931634 / E-mail: jd@emi.dtu.dk \\ ${ }^{2}$ Geodynamics Department \\ National Survey and Cadastre, DK-2400 Copenhagen NV, Denmark \\ Phone: +45 35875050 / Fax: +45 35875052
}

\begin{abstract}
A digital elevation model (DEM) of an ice cap in Greenland has been generated from airborne SAR interferometry data, calibrated with a new algorithm, and compared with airborne laser altimetry profiles and carrier-phase differential GPS measurements of radar reflectors deployed on the ice cap. The accuracy of the DEM is found to be $1.5 \mathrm{~m}$ and it is demonstrated that surface penetration is an important issue. Penetration depths up to $13 \mathrm{~m}$ are measured in the percolation zone. The effective penetration i.e. the bias of the interferometric height, has not previously been measured directly via comparison with GPS data and calibrated laser data.
\end{abstract}

\section{INTRODUCTION}

Monitoring changes of the ice sheet height is essential in global climate studies. Satellite radar altimetry can provide a high accuracy over the flat, central areas of the Greenland ice sheet, but it fails over sloping and undulating ice surfaces. In comparison, SAR interferometry has the potential to provide a high horizontal resolution, and the slope limitation is much less severe.

In the project 'Elevation Changes of the Greenland Ice Sheet' $\left(\right.$ ECOGIS $^{\dagger}$ ) [1] digital elevation models (DEMs) of the Geikie ice cap in East Greenland have been generated. Three techniques were used: 1) laser altimetry, 2) airborne single pass SAR interferometry, and 3) satellite repeat pass SAR interferometry, but only the first two are addressed here.

In August 1997, EMISAR [2] mapped Geikie at C-band. One month earlier a profiling laser altimeter was flown in the pattern shown in Fig. 1. Also, four trihedral radar reflectors were deployed and their 3D positions determined with carrier-phase differential GPS techniques. The same techniques were used to determine the positions of the two aircraft - presumably with an accuracy well below $0.5 \mathrm{~m}$.

Production of high quality XTI DEMs calls for a thorough calibration for navigation data errors, system parameters, and system imperfections like multipath propagation and insufficient channel isolation. A major part of this paper is dedicated to a presentation of a new calibration technique requir-

\footnotetext{
${ }^{\dagger}$ The ECOGIS project was supported by the Danish Research Councils. DCRS, supported by the Danish National Research Foundation, has contributed to the EMISAR development and the EMISAR flights.
}

ing no ground control points (GCP) for relative calibration and a single GCP for absolute calibration. Avoiding GCPs is particularly important in poorly surveyed, remote areas.

The second issue of this paper is a comparison of the SAR DEM with the laser data and the GPS data.

\section{CALIBRATION}

Usually, EMISAR XTI data are successfully calibrated with an algorithm that extracts calibration parameters from a dedicated calibration scene with known topography, e.g. a sea surface mapped on the same flight [3], [4]. The extension of one Geikie track over the Scoresbysund fjord constituted such a calibration scene. This technique does not require any GCPs. For the Geikie experiment, however, the algorithm proved insufficient, one reason being a difference in the look angles for the ice cap and the fjord. The slant range offset was kept constant but the elevations differ by more than $2000 \mathrm{~m}$.

Therefore a new calibration algorithm was derived. This algorithm does not require any calibration scene and it does not require the SAR system to be stable from the mapping of the calibration scene to the mapping of the scene of interest.

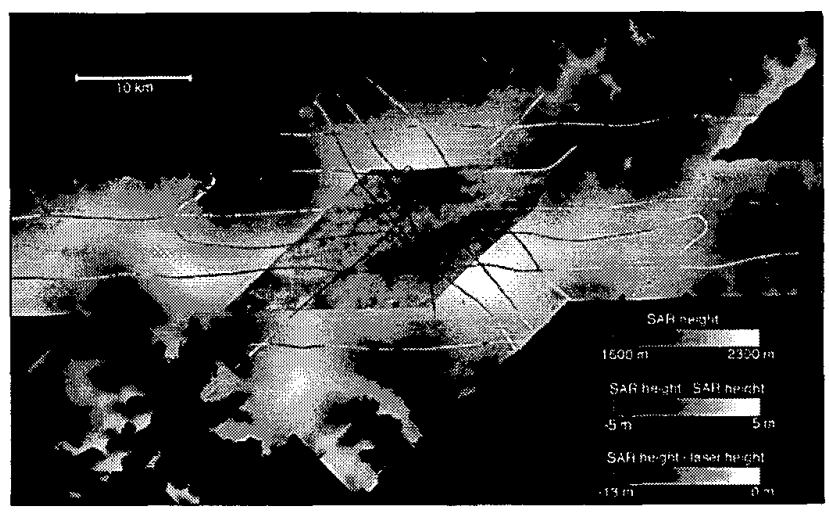

Fig. 1 Geikie ice cap height model measured with EMISAR. The rhombic overlay is the height difference between the W-E oriented strip and the middle of the three SW-NE strips. The intensity of the laser altimeter tracks is proportional to the SAR/laser height difference (black means SAR penetration). The four radar reflectors are indicated with black squares. 
Stability during each mapping suffices. On the other hand the new algorithm provides but a relative calibration. It must be complemented with other techniques for removal of a constant height offset if absolute calibration is needed.

The algorithm is based on the difference between two SAR DEMs generated from data acquired on crossing tracks. In the following the algorithm is referred to as the crossing track calibration algorithm (XTC). The sensitivity of the measured terrain height, $h$, to an error in the measured interferometric phase, $\phi$, is given by [3]

$$
\begin{aligned}
& \frac{\partial \mathrm{h}}{\partial \phi}=\frac{-\mathrm{c}}{\sqrt{\gamma^{2}-\phi^{2}}} \Rightarrow \Delta \mathrm{h}=\frac{-\mathrm{c}}{\sqrt{\gamma^{2}-\phi^{2}}} \Delta \phi \\
& \gamma=2 \pi \mathrm{pB} / \lambda
\end{aligned}
$$

where $\mathrm{c}$ is the ground range, $\mathrm{B}$ the baseline length, and $\lambda$ the wavelength. The parameter $\mathrm{p}$ equals 1 in single baseline mode (transmit on one antenna, receive on both) and 2 in double baseline mode (transmit and receive on one antenna, then transmit and receive on the other).

Likewise, the sensitivities to errors in the baseline length, $B$, the baseline elevation angle (or roll angle), $\alpha$, and the platform altitude, $\mathrm{H}$, are [4]

$$
\begin{array}{lll}
\frac{\partial \mathrm{h}}{\partial \mathrm{B}}=\frac{\mathrm{c} \phi}{\mathrm{B} \sqrt{\gamma^{2}-\phi^{2}}} & \Rightarrow \Delta \mathrm{h}=\frac{\mathrm{c} \phi}{\mathrm{B} \sqrt{\gamma^{2}-\phi^{2}}} \Delta \mathrm{B} \\
\frac{\partial \mathrm{h}}{\partial \alpha}=\mathrm{c} & \Rightarrow \Delta \mathrm{h}=\mathrm{c} \Delta \alpha \\
\frac{\partial \mathrm{h}}{\partial \mathrm{H}}=1 & \Rightarrow \Delta \mathrm{h}=\Delta \mathrm{H}
\end{array}
$$

The phase error, baseline length error, and baseline angle errors, can be corrected collectively with a phase correction $\Delta \phi(\phi)$, i.e. with a function of $\phi$ only. The equivalent phase errors corresponding to $\Delta \mathrm{B}$ and $\Delta \alpha$ are found by replacing $\Delta \mathrm{h}$ in (1) by $\Delta \mathrm{h}$ in (3) and (4), respectively

$$
\begin{aligned}
\Delta \phi(\phi) & =-\frac{\phi}{\mathrm{B}} \Delta \mathrm{B} \\
\Delta \phi(\phi) & =-\sqrt{\gamma^{2}-\phi^{2}} \Delta \alpha
\end{aligned}
$$

An altitude error, however, cannot be expressed as an equivalent phase error of $\phi$ only

$$
\Delta \phi(\phi, c)=-\frac{\sqrt{\gamma^{2}-\phi^{2}}}{c} \Delta H
$$

For instance, an altitude error of $\Delta \mathrm{H}=20 \mathrm{~m}$ requires an (equivalent) phase correction of $-\Delta \phi=0.65$ for a target at sea level, but this phase correction would leave $5.25 \mathrm{~m}$ of residual altitude error for a target at an elevation of $2000 \mathrm{~m}$. Here, typical EMISAR parameters have been assumed, i.e. a flight altitude of $\mathrm{H}=25000 \mathrm{ft}$, a look angle of $45^{\circ}$ (corre- sponding to $\phi=-48 \mathrm{rad}$ ), and a baseline with $\mathrm{B}=1.14 \mathrm{~m}, \alpha$ $=34^{\circ}$ and $\mathrm{p}=2$.

For a target at $\mathbf{r}$, the XTC algorithm models the height difference as

$$
\begin{aligned}
\Delta h(r) & =\Delta h_{1}\left(m_{1}(r), n_{1}(r)\right)-\Delta h_{2}\left(m_{2}(r), n_{2}(r)\right) \\
& =\sum_{i=0}^{N_{1}-1} x_{i, 1} \cdot f_{i, 1}\left(\phi_{1}, c_{1}\right)-\sum_{i=0}^{N_{2}-1} x_{i, 2} \cdot f_{i, 2}\left(\phi_{2}, c_{2}\right)
\end{aligned}
$$

where $\phi_{j}=\phi\left(m_{j}, n_{j}\right), c_{j}=c\left(m_{j}, n_{j}\right)$, and $\left(m_{j}, n_{j}\right)=$ (line, sample) of DEM $j, j \in\{1,2\}$. Note that this model is invariant in the azimuth direction.

With the error model defined by (1-5), the coefficients, $x_{i, j}$, are the unknown calibration errors, $\Delta \phi, \Delta \mathrm{B}, \Delta \alpha$, and $\Delta \mathrm{H}$ and the functions, $f$, are the sensitivities - or are related to the sensitivities. For instance, the phase error of EMISAR has in addition to a constant term at least four significant sinusoidal terms introduced by multipath propagation [4]. Thus, four f-terms are the products of the sensitivity (1) and a sinusoidal

$$
\begin{aligned}
\Delta h_{j}= & \frac{\partial h}{\partial B} \Delta B_{j}+\frac{\partial h}{\partial \alpha} \Delta \alpha_{j}+\frac{\partial h}{\partial H} \Delta H_{j}+\frac{\partial h}{\partial \phi}\left(\Delta \phi_{0, j}+\right. \\
& \Delta \phi_{1, j} \sin \left(f_{\mathrm{a}} \phi\right)+\Delta \phi_{2, j} \cos \left(f_{\mathrm{a}} \phi\right)+ \\
& \left.\Delta \phi_{3, j} \sin \left(\mathrm{f}_{\mathrm{b}} \phi\right)+\Delta \phi_{4, \mathrm{j}} \cos \left(\mathrm{f}_{\mathrm{b}} \phi\right)\right)
\end{aligned}
$$

where the frequencies $f_{a}$ and $f_{b}$ are known a priori.

Equation (9) can alternatively be used without an error model. In this case Chebyshev polynomials, $T_{i}$, are conveniently used to estimate an equivalent phase error $\Delta \phi_{j}$

$$
\Delta h_{j}=\frac{\partial h}{\partial \phi} \Delta \phi_{j}=\frac{\partial h}{\partial \phi} \sum_{i=0}^{N_{j}-1} x_{i, j} T_{i}(s(\phi)), \quad j \in\{1,2\}
$$

$\mathrm{i}$ is the degree of the polynomial, and $\mathrm{s}$ is a (linear) mapping of the $\phi$ interval of interest onto the interval ]-1,1[ where the Chebyshev polynomials are orthogonal. It is not possible to estimate the constant term of both $\Delta h_{1}$ and $\Delta h_{2}$ as these terms cannot be separated when only $\Delta h_{1}-\Delta h_{2}$ is known. This makes (9) ill-conditioned unless special precautions are taken ( $\mathrm{x}_{0,1}$ set to 0 and $\Delta \phi_{\mathrm{j}}$ transformed).

Each of the P pixels in the DEM overlap provides one $\Delta h$ observation, i.e. one equation in the linear model

$$
\begin{gathered}
\Delta=\mathbf{F} \cdot \mathbf{X}+\mathbf{N}, \quad \Delta=\left[\begin{array}{c}
\Delta \mathrm{h}^{1} \\
\vdots \\
\Delta \mathrm{h}^{\mathrm{P}}
\end{array}\right], \quad \mathbf{X}=\left[\begin{array}{c}
\mathrm{x}_{0,1} \\
\vdots \\
\mathrm{x}_{\mathrm{N}_{1}-1,1} \\
\mathrm{x}_{0,2} \\
\vdots \\
\mathrm{x}_{\mathrm{N}_{1}-1,2}
\end{array}\right] \\
\mathbf{F}=\left[\begin{array}{cccccc}
\mathrm{f}_{0,1}^{1} & \cdots & \mathrm{f}_{\mathrm{N}_{1}-1,1}^{1} & -\mathrm{f}_{0,2}^{1} & \cdots & -\mathrm{f}_{\mathrm{N}_{1}-1,2}^{1} \\
\vdots & \ddots & \vdots & \vdots & \ddots & \vdots \\
\mathrm{f}_{0,1}^{\mathrm{P}} & \cdots & \mathrm{f}_{\mathrm{N}_{1}-1,1}^{\mathrm{P}} & -\mathrm{f}_{0,2}^{\mathrm{P}} & \cdots & -\mathrm{f}_{\mathrm{N}_{1}-1,2}^{\mathrm{P}}
\end{array}\right]
\end{gathered}
$$


where $\mathbf{N}$ is a noise vector. The maximum likelihood estimator for the linear model (12) is found with a standard technique. Assuming polynomials of degree 10 and a typical EMISAR mapping geometry, Fig. 2 shows the condition number of $\mathbf{F}^{\mathrm{T}} \mathbf{F}$. If one scene is already calibrated, the left half of $\mathbf{F}$ and the upper half of $\mathbf{X}$ are removed and the condition number, becomes $20-30 \%$ better. The condition number is not very sensitive to the relative track angle, but (12) becomes more ill-conditioned if the DEM overlap is not rhombic, e.g. when the strips are short and fairly parallel.

\section{DATA COMPARISON}

The accuracy of the SAR DEM has been evaluated. Firstly, the RMS height errors estimated from the rhombic intersection in Fig. 1 and the two neighbouring intersections are 1.3 $\mathrm{m}, 1.3 \mathrm{~m}$, and $1.5 \mathrm{~m}$, respectively. A potential absolute height error, cancelling from the difference, is not included.

Next, the DEM has been compared with the GPS positions of the radar reflectors. The standard deviation of the height differences is $0.8 \mathrm{~m}$. The mean is not interesting as the reflectors were used for removal of a constant height offset from the DEM. A horizontal error of $4.8 \pm 0.8 \mathrm{~m}$ is found. This accuracy has been achieved by utilizing the EMISAR navigation data in a fully automated way.

Finally, the difference between the DEM and the laser altimeter heights has been analysed. The standard deviation in the percolation zone, where the signal-to-noise ratio is high, is about $1.5 \mathrm{~m}$. As seen from Fig. 1 and from a plot of the height difference versus the elevation [5], the mean difference changes from $0 \mathrm{~m}$ in the soaked zone below $1900 \mathrm{~m}$ to $13 \mathrm{~m}$ at $2275 \mathrm{~m}$ elevation. The height difference profiles have been interpolated and Fig. 3 shows that the contour lines of the penetration depth follow those of the ice elevation. The differences between the SAR-measured heights of each reflector and its surroundings are consistent with Fig. 3 and [5], and these observations are independent of calibration.

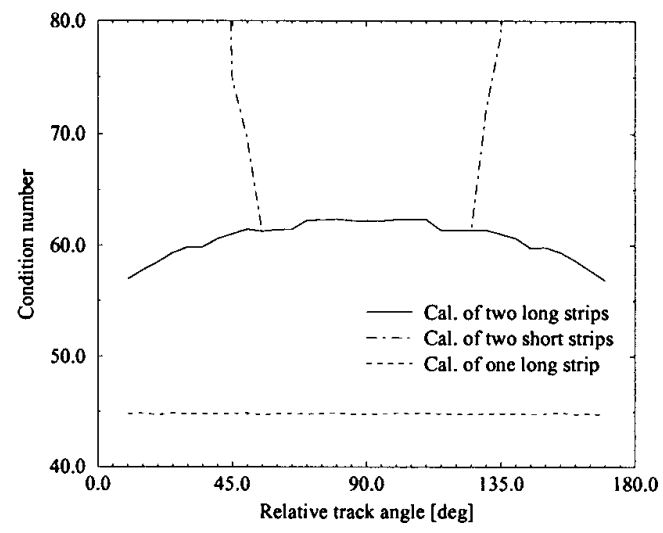

Fig. 2 The solid and dot-dash curves coincide for relative track angles between $53^{\circ}$ and $127^{\circ}$. Outside this interval the short strips do not have a rhombic overlap and the condition number increases. The short strips are here co-centered and have a length twice the width.

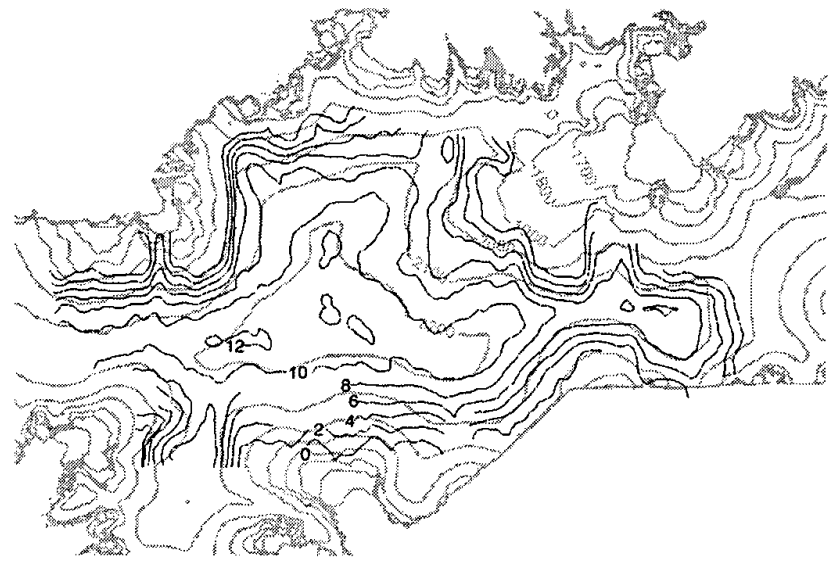

Fig. 3 Elevation of the Geikie ice cap (thick grey contour lines) and penetration depth (thin black contour lines).

\section{CONCLUSIONS}

A new algorithm for interferometric SAR calibration has been presented. System stability is only required during mapping and one GCP suffices if absolute calibration is needed, otherwise none.

The RMS accuracy of the SAR DEM is about $1.5 \mathrm{~m}$ at high elevations where the backscatter is strong. The large penetration, however, adds to the observed height 'noise'. The penetration depth increases from $0 \mathrm{~m}$ in the soaked zone to $13 \mathrm{~m}$ in the percolation zone, where the snow is relatively transparent [6].

\section{ACKNOWLEDGMENTS}

We thank Cecilia S. Nielsen for contributions to GPS processing and ice velocity estimation. Johan J. Mohr is thanked for radar reflector design and Steen S. Kristensen for radiometric SAR calibration. All contributed to the field work.

\section{REFERENCES}

[1] R. Forsberg, K. Keller, C.S. Nielsen, N. Gundestrup, C.C. Tscherning, S.N. Madsen, J. Dall, "Elevation change GPS measurements of the Greenland ice sheet", Earth, Planets and Space (Proc. GPS-99 conference, Tokyo), in press, 2000.

[2] S.N. Madsen, N. Skou, J. Granholm, K. Woelders, and E.L. Christensen, "A system for airborne SAR interferometry", Int. J. Electronics and Communications, Vol. 50, No. 2, pp. 106-111, 1996.

[3] S.N. Madsen, N. Skou, K. Woelders, and J. Granholm, "EMISAR single pass topographic SAR interferometer modes", Proc. Int. Geosci. and Remote Sens. Symp., IGARSS'96, pp. 674-676, 1996.

[4] J. Dall, J. Grinder-Pedersen, S.N. Madsen, "Calibration of a high resolution airborne 3-D SAR", Invited Paper, Proc. Int. Geosci. and Remote Sens. Symp., IGARSS'97, pp. 1018-1021, 1997.

[5] J. Dall, S.N. Madsen, K. Keller, R. Forsberg, "Topography and penetration of the Greenland ice sheet measured with airborne SAR interferometry", unpublished.

[6] E.J. Rignot, S.J. Ostro, J.J. Van Zyl, and K.C. Jezek, Unusual radar echoes from the Greenland ice sheet, Science, Vol. 261, pp. 1710$1713,1993$. 